\title{
MAPPING GREEN INFRASTRUCTURE ELEMENTS BASED ON AVAILABLE DATA, A CASE STUDY OF THE CZECH REPUBLIC
}

\author{
HANA SKOKANOVÁ*, INÉS LASALA GONZÁLEZ, TOMÁŠ SLACH
}

\author{
Silva Tarouca Research Institute for Landscape and Ornamental Gardening, \\ Lidická 25/27, 60200 Brno, Czech Republic \\ *Corresponding authore-mail: hanka@skokan.net
}

Received: $27^{\text {th }}$ April 2020, Accepted: $6^{\text {th }}$ May 2020

\begin{abstract}
The contribution of Green Infrastructure (GI) in vital areas such as regional development, climate change, agriculture, forestry and environmental protection is already acknowledged and listed as one of the priorities in several key EU policies, and is the basis for the EU Green Infrastructure Strategy. However, the concept is not yet fully integrated into actual planning strategies, in this respect the Czech Republic is no different. A major problem in doing so is a lack of guidelines/ how to identify and map GI using available sources and thus keeping costs down. The existing data sources for land cover or land use often do not fulfil the requirements in terms of thematic coverage, resolution or accuracy. In order to work around such limitations, we analyse the existing land use/land cover data in the Czech Republic from the GI perspective. Furthermore, we propose a GI mapping methodology based on the diagnosis of three mapping approaches at the regional level, grounded on the utilisation and processing of different data sets. We compared GI maps based on European data from CORINE Land Cover Database, Czech national database called Consolidated Layer of Ecosystems (CLE) and combination of Czech national and regional data and manual vectorization. Our results show that CORINE based GI map is suitable for transnational scale but unsuitable for regional scale. The CLE based GI map is good for both national and regional scale but its information on GI in urban areas is lacking. The detailed regional GI map is good for regional and to some degree even for local scale but its creation is time consuming. However, careful combination of existing national and regional data can provide good outcome in creating GI map usable for territorial planning.
\end{abstract}

Keywords: green infrastructure, mapping, available data, Czech Republic

\section{INTRODUCTION}

Although the term Green Infrastructure (GI) was first appointed in mid-1990's in the United States (Firehock, 2010), it has gained more attention worldwide in the last decade, especially within discussions dealing with landscape protection and territorial development. According to the European Commission (2013) GI can be broadly defined as a strategically planned network of high quality natural and semi-natural areas with other environmental features, which is designed and managed to deliver a wide range of ecosystem services and 
Skokanová H.,González I.L., Slach T.: Mapping Green Infrastructure elements based on available data, a case study of the Czech Republic

protect biodiversity in both rural and urban settings. This definition considers three important concepts, linked to key principles of sustainability: a network of areas - ecological connectivity, the concept of ecosystem services - multifunctionality, and protection of biodiversity - conservation. However, it also infers that GI is more than just conservation areas and includes other "green" elements, especially occurring in the cities, like green walls and roofs or urban parks.

In the European context, the development and conservation of GI elements is listed as one of the priorities in several key EU policies areas (e.g. The EU Climate Change Strategy). GI can make a significant contribution in the areas of regional development, climate change, disaster risk management, agriculture/forestry and the environment (European Commission, 2013). Although in most of the cases, the contribution of GI is already acknowledged, it is important at present to ensure that the promotion and deployment of GI is fully integrated into policy implementation in key sectors, so that the support of the associated funding mechanisms is guaranteed. A potential way to achieve such goal is by incorporating GI into territorial planning.

In order to support the integration of GI into the territorial planning process it is important to identify GI and to establish a mapping methodology to achieve a good assessment and diagnosis. Spatial delineation of GI elements has often been based on a re-classification of available land cover data combined with information about the natural values of each cover class (Liquete et al., 2015). However, the existing land cover data sources worldwide and even within the European context, often differ significantly between countries, and so do their characteristics such as thematic coverage, resolution, approach, accuracy and/or availability. Moreover, GI elements are often integrated within usually complex categories, e.g. settlements (urban green spaces, gardens, smallholdings, etc.), resulting in much higher heterogeneity at finer scale. In order to overcome this discrepancy, conventional mapping methods have relied on visual interpretation of aerial imagery and fieldwork, aiming to increase the accuracy of GI identification in impervious-vegetated mix areas (Rosina \& Kopecká, 2016). More recently, very high resolution (VHR) satellite remote sensing systems (IKONOS, QuickBird, GeoEye, RapidEye, WorldView, Pleiades) are capable of providing imagery with similar detail to aerial photography across large areas (Kopecká et al., 2017), resulting in the improved capturing GI elements within complex categories, such as settlements. However, the use of VHR imagery and remote sensing techniques for GI mapping, involves sophisticated software and procedures, which often require expertise. Therefore they are not always suitable for regional or local planners when forming the territorial planning strategy/ developing the territorial plan.

In the Czech Republic, both GI and ecosystem services assessment are still new topics. Efforts to somehow assess ecosystem services, or rather value/multifunctionality of biotopes reach back to 1970s (Seják, 2010). The newest contribution to the assessment of ecosystem services is represented by a methodological framework of the integrated assessment of ecosystem services in the Czech Republic. The framework stipulates basic rules and procedures for evaluating the state of ecosystems, ecosystem services and their economic value (Vačkáŕ et al., 2015). This framework is supported by a Consolidated Layer of Ecosystems that serves as a map resource for an assessment of ecosystem services.

While assessment of ecosystem services is thus far not a widely spread concept in the Czech Republic, there is a tool in territorial planning that is well established and to some point fulfils one of GI's concepts, namely ensuring the presence and connectivity of natural and semi-natural ecosystems/habitats. It is called the Territorial System of Ecological Stability of the Landscape (TSES) and is an integral part of territorial plans for each municipality. It is defined as an interconnected system of natural as well as modified but near 
natural ecosystems keeping the natural balance (Act No. 114/1992) and consists of three different main groups of elements: bio-centres, bio-corridors, and interactive elements. A bio-centre is a habitat or a system of habitats, which ensures by its status and size the permanent existence of natural or semi-natural ecosystems and is interconnected with other bio-centres. Bio-corridors are areas, often elongated, which enable the movement of organisms between bio-centres, but do not necessarily provide the optimal habitat conditions for a long-term existence of such organisms (e.g. a hedge between woodlands). Interactive elements are landscape segments, spatially isolated, delivering favourable conditions for the permanent existence of organisms with limited territorial requirements, creating stepping stones. All these elements together should form functional network on three levels (supra-regional, regional and local). There are predefined minimum parameters that these elements should have to be functional (Bínová et al, 2017; Löw et al., 1995). The TSES is a designed and to some extent aspirational network, i.e. not all components are currently present in the landscape - missing ones should be first delineated in a territorial plan and subsequently created in the landscape. TSES concept does not cover all GI elements but focuses mainly on the natural ones. Therefore, it could be considered only as a part of GI. The advantage of TSES is that it addresses one of the key GI concepts - connectivity. It is an ecological network (Buček et al., 2012), based on biogeographical landscape differentiation in geobiocoenological conception (Buček et al., 2015), which secures physical links among habitats, ensuring uninterrupted movement of organisms and is similar to other ecological networks in Europe, e.g. Germany (Jedicke, 1994), Slovakia (Topercer, 2013) or Netherlands (Lammers \& Zadelhof, 1996).

In planning, implementing, and managing Green Infrastructure it is important to consider the spatial scales i.e. national, regional and local, and which is most appropriate to the process or functions under consideration (Collective, 2010). Supra-national level also plays an important role at the European level since most European policies have a transnational approach. The national level should facilitate trans-boundary and international linkages, allowing strategies to be put in the context of larger international concerns (i.e. climate change, connectivity, etc.). The regional level should provide linkages across local authorities and other organisations and use a wider range of data that provide additional understanding and detail for planning and mapping. The local level should facilitate the local authorities' involvement at county and sub-county levels, and deliver an appropriate map for detailed assessment or planned implementations. The flow of information and data should move up and down the scales but also horizontally at regional and local levels (Collective, 2010).

The aim of this paper is to analyse the existing land cover data that is currently available in the Czech Republic for mapping GI, according to different mapping levels by comparing different data sources: CORINE data, representing trans/national level, Consolidated Layer of Ecosystems (CLE), representing national/regional level, and collection of available existing data in combination with manual vectorisation, representing more detailed regional/local level. Derived GI maps from these databases will be further referred to as CORINE GI map, CLE GI map and detailed regional GI map. The paper also tries to answer following questions: a) are the used data sufficient for identification of GI in respective levels? b) what are the strengths? and c) what are the biggest issues of using available sources and how can we overcome them? The study is part of an international Interreg Central Europe project Managing Green Infrastructure in Central European Landscapes (MaGICLandscapes), which among others focused also on classification and mapping GI across Central Europe and case study regions from Austria, Czech Republic, Germany, Italy and Poland. 


\section{STUDY AREA}

Kyjovsko is a lowland region situated in the southeast of the Czech Republic, in South Moravia. Its size is $470 \mathrm{~km}^{2}$ (Figure 1).

Fig. 1: Location of study area Kyjovsko in the Czech Republic

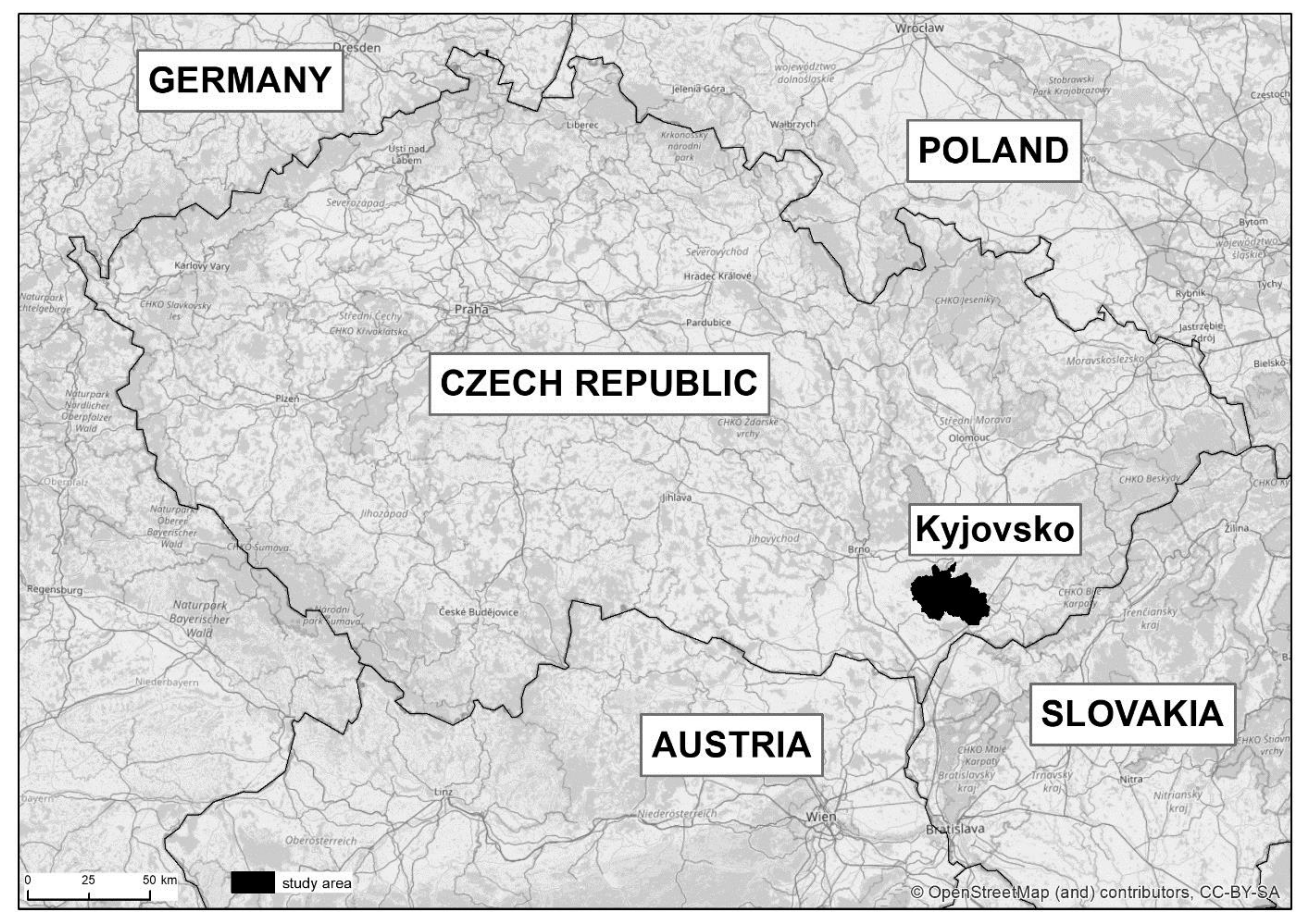

Most of this area is intensively used, especially for agriculture, resulting in very large, impermeable blocks of arable fields that suffer from wind and water erosion. Due to its warm and dry climate (average annual temperature is around $9{ }^{\circ} \mathrm{C}$ and average annual precipitation around 450-500 mm), the region is known for its vineyards and to a lesser extent also for its orchards, which unfortunately are quickly disappearing. Larger forest complexes can be found in the north (mostly deciduous, dominated by oak and hornbeam) and in the south of Kyjovsko (predominantly coniferous - pine forests on sandy soils). There are also some remnants of dry grasslands. One of the unique but rapidly disappearing features of the landscape is the mosaic of smallholdings - a mixture of vineyards, orchards, arable fields and grasslands, usually connected with settlements. Furthermore, due to land consolidation during socialist period, the landscape became harder to access, so improved permeability both for people and wildlife is needed. Additionally, in recent years, the region has suffered from drought (Trnka et al., 2016). 


\section{MATERIALS AND METHODS}

\section{Data sources}

For the trans/national level, CORINE Land use/Land cover database from 2012 was used. This database is freely available from European Environment Agency web page. It is vector based, with resolution/minimum mapping unit (MMU) of 25 ha and minimum width of $100 \mathrm{~m}$.

The databases on land cover/land use currently available in the Czech Republic that have been used for the different regional GI mapping approaches are listed and briefly described in Table 1. The table contains information on the data source, data type and its resolution. It also includes the coverage, reference year, and some remarks on its availability. All the data sources in the table were directly or indirectly used in the GI mapping at a regional level. A direct use implied no need to modify/edit the dataset in order to represent the majority of the GI elements present in the landscape. An indirect use entailed the manual modification/editing of the data either for representing GI elements that were missing or for improvement of accuracy. In some cases, an indirect-use-data source also meant verification source or reference.

\section{GI identification and classification.}

The GI identification was mainly based on the aforementioned definition from the European Commission (2013). Thus, every green or blue element in the landscape whether natural, semi-natural or anthropogenic that may provide ecosystem services, was considered Green/Blue infrastructure and integrated into the map.

The GI classification scheme presented in this work is based on CORINE Land Cover (CLC), in order to allow the comparison of results in the transnational approach. The original classification scheme was agreed within the MaGICLandscapes project (Ed. 2019). For the regional mapping level, it has been adjusted in order to capture level of naturalness (Table 2). Therefore, the GI classes in narrow sense included only natural or semi-natural ecosystems. GI under specific circumstances (or specific GI) were represented by ecosystems created and regularly managed by human activities. Without them, these ecosystems would cease to exist. From the no GI/BI group, discontinuous urban fabric might be problematic, since according to its definition it includes not only impervious surfaces, such as buildings or parking spaces, but also gardens. The same can be said also for non-irrigated arable land and road and rail networks and associated land. Both classes according to their definition can also obtain some GI elements in the form of woody and grassland strips. However, for regional purposes these elements can be assigned to either green urban areas or land principally occupied by agriculture, with significant areas of natural vegetation (further mentioned as agricultural land with natural vegetation). 
\&

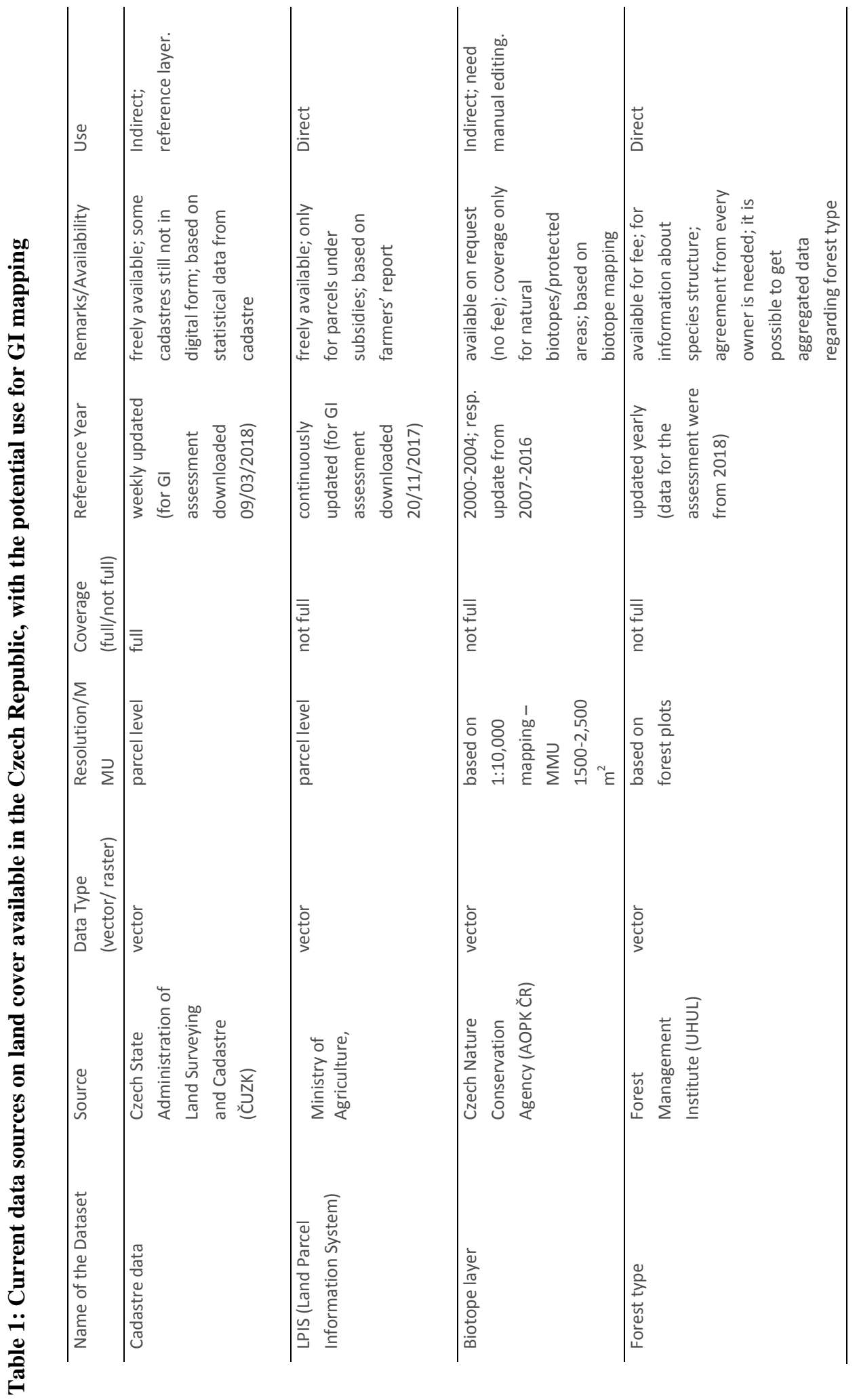


a

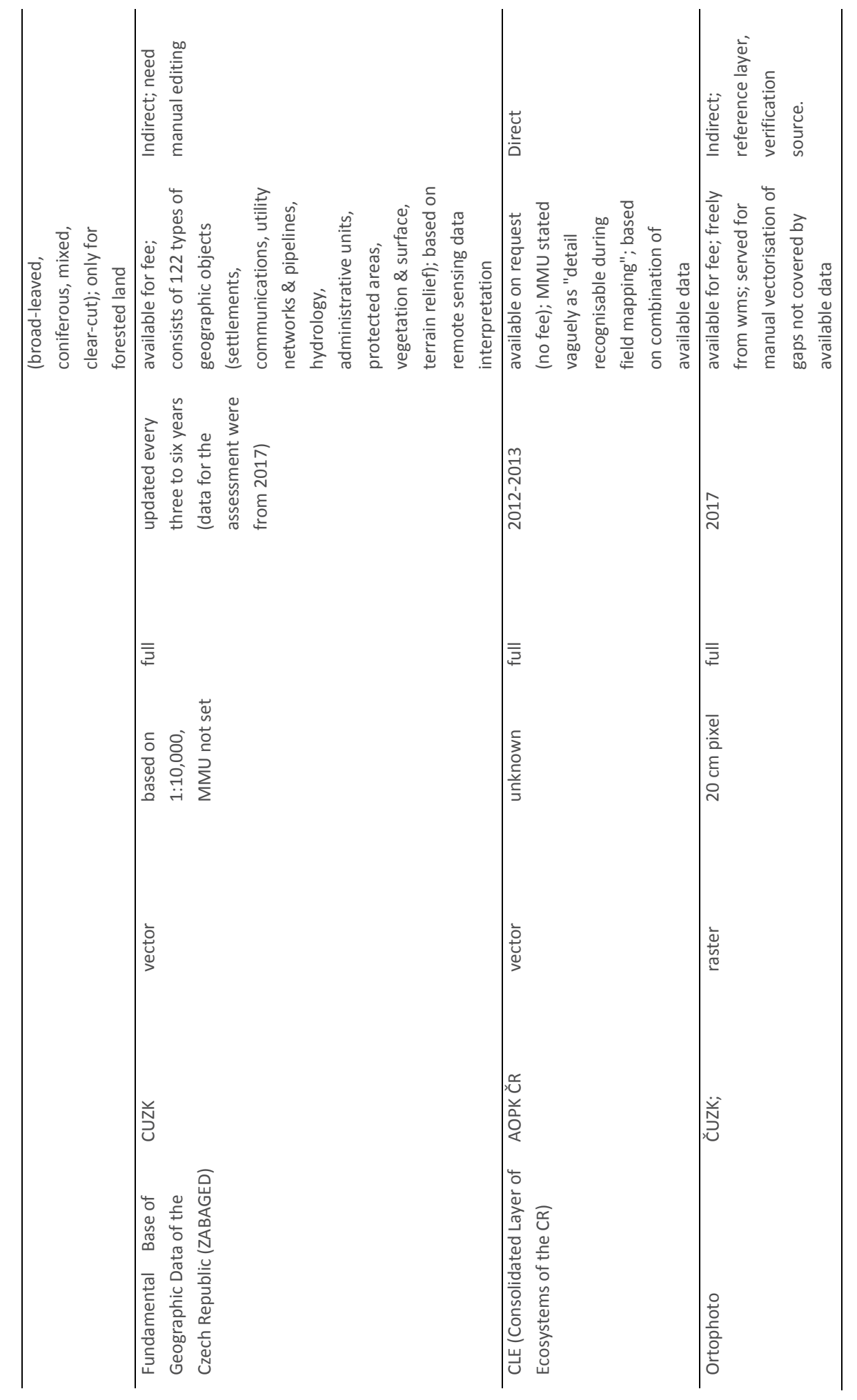


Table 2: Classification scheme adjusted to the regional mapping level

\begin{tabular}{|c|c|c|c|}
\hline & CLC Code & Description & Comments \\
\hline \multirow{8}{*}{ 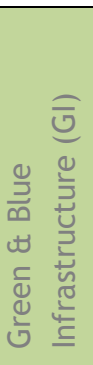 } & 311 & Broad-leaved forests & \\
\hline & 312 & Coniferous forests & \\
\hline & 313 & Mixed forests & \\
\hline & 321 & Natural grasslands & \\
\hline & 324 & Transitional woodland-shrub & \\
\hline & 411 & Inland marshes & \\
\hline & 511 & Water courses & \\
\hline & 512 & Water bodies & \\
\hline \multirow{7}{*}{ 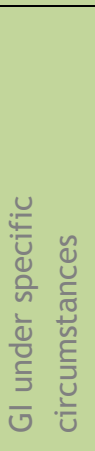 } & 141 & Green urban areas & Include also gardens. \\
\hline & 221 & Vineyards & Only small and/or extensively used. \\
\hline & 222 & Fruit trees and berry plantations & Only small and/or extensively used. \\
\hline & 231 & Pastures & $\begin{array}{l}\text { Also include grassland strips along } \\
\text { roads }\end{array}$ \\
\hline & 242 & Complex cultivation patterns & Landscape mosaics, smallholdings. \\
\hline & 243 & $\begin{array}{l}\text { Land principally occupied by agriculture, } \\
\text { with significant areas of natural vegetation }\end{array}$ & $\begin{array}{l}\text { Namely non-forest woody } \\
\text { vegetation. }\end{array}$ \\
\hline & 244 & Agro-forestry areas & $\begin{array}{l}\text { In current situation mainly fields } \\
\text { with fast growing trees. }\end{array}$ \\
\hline \multirow{8}{*}{$\begin{array}{l}\bar{\oplus} \\
\text { ৩ } \\
\text { 은 }\end{array}$} & 111 & Continuous urban fabric & \\
\hline & 112 & Discontinuous urban fabric & \\
\hline & 121 & Industrial or commercial units & \\
\hline & 122 & Road and rail networks and associated land & \\
\hline & 131 & Mineral extraction sites & \\
\hline & 133 & Construction sites & \\
\hline & 142 & Sport and leisure facilities & \\
\hline & 211 & Non-irrigated arable land & \\
\hline
\end{tabular}

\section{Mapping approaches and accuracy assessment.}

This work includes three GI mapping approaches based on the type of datasets used. The regional level was chosen as the spatial level to show the results on GI mapping in the Czech Republic context. The data were processed and classified using ESRI ArcGIS Desktop 10.3-10.5 software.

\section{CORINE GI map}

CLC level 3 dataset from 2012 was obtained in a vector format from European Environment Agency - Copernicus Land Monitoring Services. This dataset divides landscape into 44 classes in the hierarchical 3-level CORINE nomenclature. To assess accuracy of identified classes, 1,000 randomly distributed points were generated and ground-truthed. The ground-truthing process consisted of visual verification of a selection of these points on satellite imagery from the same year (GioLand 2012) and was carried out at scale 1:5,000. Verification revealed overall accuracy being approximately $84 \%$ (Skokanová, 2018).

GI map was derived by dividing existing classes into three groups as stated in Table 2. 


\section{CLE GI map}

The CLE layer was produced by the Nature Conservation Agency of the Czech Republic and CzechGlobe - Global Change Research Institute of the Czech Academy of Sciences during 2012-2013 (AOPK ČR, 2013). It combines the following input data - Habitat Mapping Layer (Biotope layer), Fundamental Base of Geographic Data of the Czech Republic (ZABAGED), Digital Base of Water Management Data (DIBAVOD), Copernicus Land Monitoring Service (Urban Atlas) and CORINE Land Cover. The primary data sources were Biotope Layer, DIBAVOD and ZABAGED. The rest of the data served to fill in the missing information.

The layer can enable differentiation of both natural and anthropogenic ecosystems at a resolution suitable for ecosystem services assessment at regional and national levels. It divides the landscape into 41 main categories of ecosystems in four hierarchical levels and six broader types of ecosystems (AOPK $\check{C} \mathrm{R}, 2013$ ). These categories were reclassified and rendered into the CLC classification.

GI map was derived by dividing existing classes into three groups as stated in Table 2.

\section{Detailed regional GI map}

Similarly to the CLE map, a combination of several land cover data sources available in the Czech Republic were used to map GI in Kyjovsko region (Table 3). As shown in the table, some of the GI classes were directly represented by certain categories comprised in the datasets. However, manual editing of some of the existing layers and manual delineation of missing GI elements was needed in order to provide full coverage of GI on a regional scale map.

Regarding the sources, the most precise and up-to-date layers were the LPIS and Forest type. The precision was assured by the fact that these layers are based on annual update from the owners and users of relevant plots. Unfortunately, LPIS database only includes information on plots under agricultural subsidies. Therefore, additional information from ZABAGED had to be added to capture all plots with agricultural use, especially concerning vineyards and fruit trees and berry plantations. Forest type layer covers only plots considered as forest land by definition from Forest Act (No. 289/1995 Coll.). Biotope layer was used to capture more natural elements. This was true especially for inland marshes and somewhat for natural grasslands and agricultural land with natural vegetation. Unfortunately, biotope layer does not include all plots where natural elements could occur. Therefore, additional layers (LPIS, ZABAGED, UHUL-forest type) had to be used as well.

The most problematic classes to map were transitional woodland-shrub (CLC code 324), complex cultivation patterns (242) and agricultural land with natural vegetation (243). These classes are complex and can include several landscape elements. Transitional woodland-shrub includes not only clear-cuts (from Forest type layer) but also shrubs (from Biotope and ZABAGED layers) or meadow orchards (not classified in any existing database). Complex cultivation patterns are a mixture of small orchards, vineyards, arable fields and grasslands, which are captured to some degree in several layers (ZABAGED and Cadastre). However, these layers do not cover the exact extent of the class and had to be edited with the use of 2017 orthophoto. Agricultural land with natural vegetation includes mainly non-forest woody vegetation that are also largely not classified in any existing database. Therefore, these classes had to be significantly edited with the use of 2017 orthophoto as well. Also green urban areas were quite difficult to delineate. This was true especially for gardens on the periphery of settlements that could be mixed with complex cultivation patterns. Combination of ZABAGED and Cadastre layers provided basis for this class and additional manual editing with the use of 2017 orthophoto was applied. 
Table 3: Land cover data sources used for the GI map of Kyjovsko based on the suggested procedure

\begin{tabular}{|c|c|c|c|}
\hline & CLC Code & GI Class & Source \\
\hline \multirow{8}{*}{ 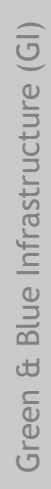 } & 311 & Broad-leaved forests & Forest type \\
\hline & 312 & Coniferous forests & Forest type \\
\hline & 313 & Mixed forests & Forest type \\
\hline & 321 & Natural grasslands & Biotope layer, LPIS, ZABAGED \\
\hline & 324 & Transitional woodland-shrub & $\begin{array}{l}\text { LPIS, ZABAGED, Forest Type, Biotope } \\
\text { layer, manual editing }\end{array}$ \\
\hline & 411 & Inland marshes & Biotope layer \\
\hline & 511 & Water courses & ZABAGED (buffer) \\
\hline & 512 & Water bodies & ZABAGED \\
\hline \multirow{7}{*}{ 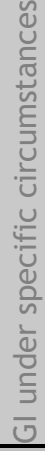 } & 141 & Green urban areas & ZABAGED, Cadastre, manual editing \\
\hline & 221 & Vineyards & LPIS, ZABAGED \\
\hline & 222 & Fruit trees and berry plantations & LPIS, ZABAGED \\
\hline & 231 & Pastures & LPIS, manual editing \\
\hline & 242 & Complex cultivation patterns & ZABAGED, Cadastre, manual editing \\
\hline & 243 & $\begin{array}{l}\text { Land principally occupied by } \\
\text { agriculture, with significant areas of } \\
\text { natural vegetation }\end{array}$ & $\begin{array}{l}\text { ZABAGED, Biotope layer, manual } \\
\text { editing }\end{array}$ \\
\hline & 244 & Agro-forestry areas & LPIS \\
\hline \multirow{8}{*}{$\begin{array}{l}\bar{\oplus} \\
\text { v } \\
\text { ㅇ }\end{array}$} & 111 & Continuous urban fabric & ZABAGED \\
\hline & 112 & Discontinuous urban fabric & ZABAGED \\
\hline & 121 & Industrial or commercial units & ZABAGED \\
\hline & 122 & $\begin{array}{l}\text { Road and rail networks and associated } \\
\text { land }\end{array}$ & ZABAGED (buffer) \\
\hline & 131 & Mineral extraction sites & ZABAGED \\
\hline & 133 & Construction sites & ZABAGED \\
\hline & 142 & Sport and leisure facilities & ZABAGED \\
\hline & 211 & Non-irrigated arable land & LPIS \\
\hline
\end{tabular}

Since road and railway networks and water courses were in a linear layer, they were transformed to polygon layer by buffering. Buffering for water courses was set to $2 \mathrm{~m}$; for road and railroad network the buffer varied depending on classification from $4 \mathrm{~m}$ (one-track railroad and field road) to $22 \mathrm{~m}$ (1st class road).

All existing layers were verified using orthophoto from 2017 and, where necessary, adjusted manually to the present situation. In some unclear cases, verification in the field was necessary. Subsequently, all layers were overlaid. This overlay revealed gaps that had to be filled in manually, again using the 2017 orthophoto. The gaps were usually linear features of 
GI that were not captured in the existing databases. Finally, individual classes were assigned into three groups from Table 2 and GI map was derived.

\section{RESULTS AND DISCUSSION}

\section{GI maps of the Kyjovsko region - scale issue}

If we compare the overall coverage of GI (Figure 2A), we will find out that CORINE GI map shows the smallest area of GI while the detailed regional GI map shows the largest area. Also the number of GI elements in the CORINE GI map is the smallest (Figure 2B) and their average area largest (Figure 2C), leading to simplified GI network (Figure 3A) with missing GI elements, such as green urban areas (including gardens), woody strips or grassland strips. Water courses and small water bodies are also missing. This outcome is not surprising due to the generalized input data and definition of CLC classes that was used during creation of CORINE map (Bossard et al., 2000).

Fig. 2: Characteristics of green infrastructure in CORINE GI map, CLE GI map and detailed regional GI map: area (A), number of elements (B) and average area (C)

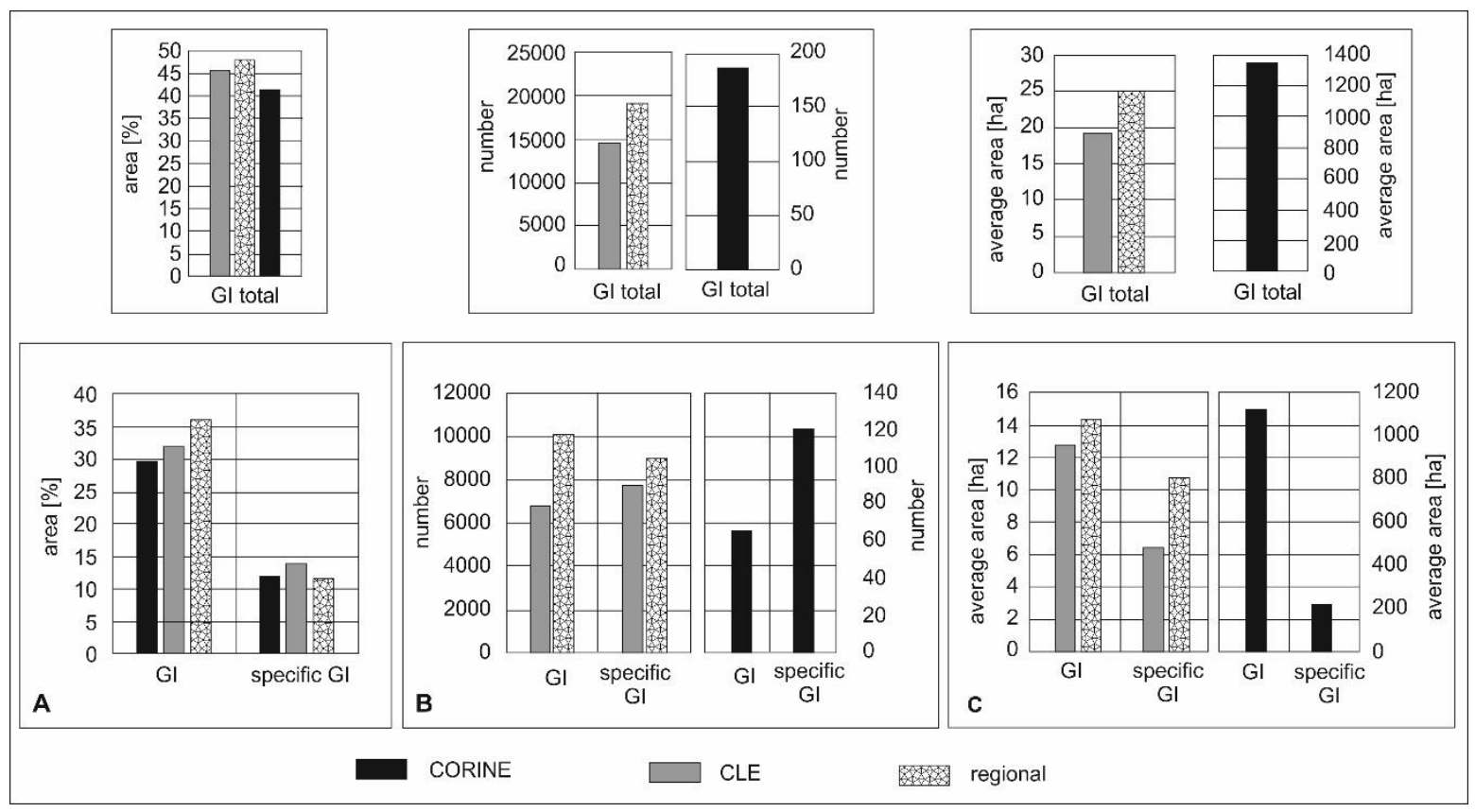

The CLE GI map shows more detail (Figure 3B), evidencing the existence of smaller scale GI in the landscape (Figure 2B and 2C), for instance within arable fields and vineyards (woody strips, forest patches, etc.). The total GI area is only $2 \%$ smaller than GI area in the regional GI map (Figure 2A). This might be largely attributed to the fact that the CLE GI map does not recognize GI elements integrated in urban areas, especially gardens, leading to underrepresentation of GI in these settings. This characteristic is the main disadvantage in mapping GI using the CLE layer.

The detailed regional GI map displays further detailed GI, especially in the urban settings (Figure 3C2), resulting in the biggest GI area and number of GI elements in the whole 
Kyjovsko region (Figure 2A, 2C). In the open landscape, the regional GI map shows a very similar landscape pattern (Figure 3C1) with respect to the CLE GI map (Figure 3B1) since some of the datasets were used in both procedures (i.e. Biotope layer or Zabaged). However, the detailed regional GI map shows GI within settlements (gardens and other green urban areas such as parks, ornamental gardens, graveyards, urban groves, hedgerows, etc.) in much greater detail. Thus, it provides a more precise overview on the distribution and characteristics of the Green Infrastructure with respect to the Grey Infrastructure.

Fig. 3: Comparison of CORINE Green Infrastructure map (A), Consolidated layer of Ecosystems (CLE) Green Infrastructure map (B), and detailed regional Green Infrastructure map (C) in open landscape (1) and urban settings (2)

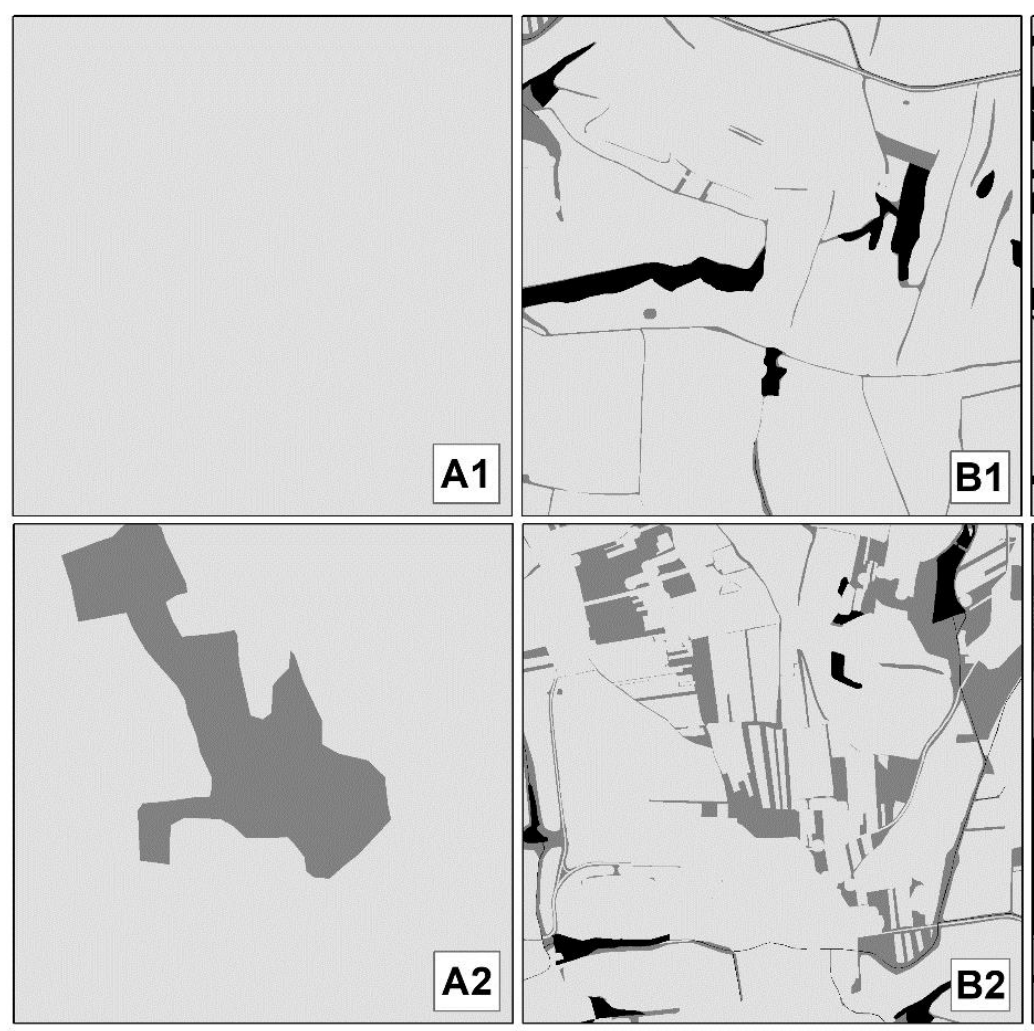

green infrastructure
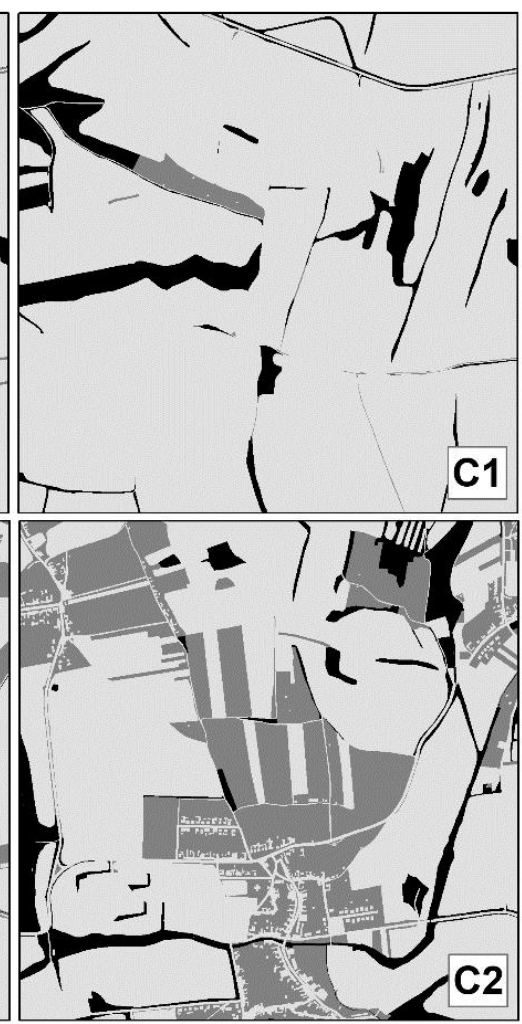

0,3

Strengths and weaknesses, coverage issues and problematic categories of the applied datasets.

The resulting GI maps of Kyjovsko clearly revealed some gaps in terms of accuracy and thematic coverage as well as some strong points regarding the existing data on land cover/land use in the Czech Republic and their use for creating GI maps. The regional mapping level is the focus of this analysis, although it applies to both national and local level as well. For obvious reasons, CORINE GI map is for regional level useless, therefore only CLE GI map and detailed regional GI map will be discussed further, with focus on individual GI classes. 
The forested areas were accurately represented by the dataset on forest composition provided by UHUL. However, this source is not freely available and therefore the utilisation of some of its data is subject to purchase and in some cases, requires the consent of the forest owners of the requested area (i.e., forest composition dataset). The UHUL institution also develops remote sensing data on forests and vegetation cover based on automated analysis of satellite imagery, infrared orthophotos and digital surface models, with a spatial resolution of $10-20 \mathrm{~m} /$ pixel. Hence, it means one more option to represent the vegetation with greater accuracy, although it does not discern amongst vegetation types (for instance forest from orchards and broad-leaved from coniferous), which could be significantly limiting when identifying individual GI classes. On the other hand, if both classes are considered as a GI and the outcome is to identify GI in general, this kind of data would be good to use. The CLE GI map uses primarily Biotope layer for identifying natural forests and a mixture of Biotope layer, ZABAGED and CORINE for identifying managed forests (AOPK 2013). This is also good option how to capture this GI class.

Permanent grasslands such as meadows and pastures were identified and mapped with great accuracy by LPIS datasets. The data source is freely available and regularly updated based on farmers' records. However, it does not provide full coverage, covering only land subjected to farming subsidies. This is also the case for orchards and vineyards. This source also provides information on the management type (ecological, transitional between ecological and conventional, or conventional/intensive) that may be considered a deciding factor when identifying GI.

Cultivated lands such as orchards, vineyards and permanent grasslands, which are not included in the LPIS data source, were covered by the ZABAGED layer. Its coverage is full, it is available for a fee but updates range from one to every three to six years. It also provides data on almost every element in the landscape and every land use. However, many of its thematic layers lack accuracy in terms of resolution and thematic coverage, as is the case for both cultivated lands and permanent grasslands.

In the CLE GI map, natural grasslands are covered within the Biotope layer, while the meadows and pastures are covered by a combination of Biotope layer and ZABAGED layer. Authors of the CLE layer decided to include complex cultivation patterns as well as agricultural land with natural vegetation into the pastures, leading to significant overestimation of meadows and pastures (9\% coverage compared to $1 \%$ coverage in the regional GI map).

The complex cultivation patterns class is one of the key classes in GI mapping and therefore its representation is vital. These small farming plots create the mosaic landscape type, so desirable in terms of biodiversity conservation, landscape connectivity and aesthetic value provision among other ecosystem services (Špulerova et al., 2018). The ZABAGED data includes a class called gardens and orchards, which partly represents some of the smallholdings in the vicinity of settlements. However, most of these smallholdings are often misrepresented or generalised and included within the orchards class. Thus, manual editing and delineation was needed in order to reclassify or redefine those plots contained in other classes or to create those not existing at all. To support the manual editing of the complex cultivation patterns, the gardens class from the Cadastre data source provided a good basis, especially in the vicinity of settlements. It is freely available and the delimitation of the plots is very accurate.

Other key GI elements often present in the agricultural landscape are the strips of vegetation or grassland, hedgerows, alleys, forest patches, groups of trees or solitary trees. These small scale features can make a significant difference, for instance in the landscape fragmentation (Agger \& Brandt, 1988; Demková \& Lipský, 2017). They can serve as 
stepping stones, bio-corridors and small-scale bio-centres. The existing datasets partly include them in the following manner: LPIS provides information on so called ecologically significant features - groups of trees, solitary trees, vegetation strips or singular elements that are again under subsidies. ZABAGED data set provides information on some small woodlots. However, both databases do not provide full coverage of these features and/or their accuracy can be lacking. Thus, it was crucial to complete the mapping process by manual delineation of such elements. Manual delineation of some of these GI elements, could be supported by the vegetation cover layer, developed by UHUL and based on remote sensing procedures. However, manual editing would be still required since only some of these features would be representing the elements of interest (some of them are parts of orchards) and some features would still be missing.

The water bodies and water courses were generally well represented in the ZABAGED datasets. This source provides information on its nature i.e. artificial or natural. ZABAGED also includes information on the wetlands. However, spatial data on wetlands, peatlands or inland marshes were more precise when derived from the Biotope layer.

The areas within settlements are essential zones to consider in the framework of GI assessment and development given the disproportion between Grey Infrastructure and green spaces that so often occurs in the urban areas. Spatial data on Grey Infrastructure (transport infrastructure, built-up, industrial units or dump sites among others) was provided by ZABAGED in very good resolution. ZABAGED also provided quite good information about GI, especially regarding public parks and ornamental gardens. Information on gardens and garden altoments was more problematic, since ZABAGED combines gardens with orchards. However, this layer can be clipped by an urban mask and combined with information from Cadastre data. The urban mask can be created following the rules described in CLE layer (AOPK, 2013), i.e. combining existing layers (other area in settlements, built-up area and purpose-built area) and buffer. Although such created layer does not capture detail, it is better to use than to omit vital information about urban GI, as was done in the CLE GI map.

\section{Methodological issues}

Including GI considerations in the planning and decision-making process will help to reduce the loss of ecosystem services associated with the future land use changes (Liquete et al., 2015), maintain ecosystem functions and enhance natural processes. Consequently, identifying, promoting and preserving a strategically planned GI network (Kopecká et al., 2017) is nowadays the focus of many studies which aim to develop a methodology that helps to identify, map and assess existing GI (e.g. Dennis et al., 2018; Liquete et al., 2015; Mander et al., 2018).

The ability to select ecological, structural and socio-economic aspects of importance for particular development plans and combine these features in comprehensive GI maps offers a versatile approach to spatial planning processes (McKenna et al., 2010). However, mapping GI is not yet an easy process, neither from the conceptual point of view nor the technical one. Firstly, the GI term has developed in response to different needs, prioritising different environmental, social and economic focuses. Although nowadays we do understand the significance of GI, its translation into policy or practical measures is still challenging, as is the way to standardise the criteria to identify it. In this regard, we found several identification discrepancies regarding where to set the line for what is considered GI and what not. This is true especially for GI under specific circumstances, i.e. GI created and regularly maintained by human activities. The scale is the main issue. For instance, in cultivated land such as arable fields, vineyards or orchards, the size of the plot was a key deciding factor. In our understanding, small plots were usually remnants of traditional management, with low inputs 
of chemicals, cultivated with the help of small machinery or in an ecologically-friendly regime; therefore provision of a wider variety ecosystem services was more likely here than in large plots. Consequently, these small plots should be part of GI. However, that raised the question on how to proceed when this type of information is not provided; or how to unify criteria in such different environments where the same element could mean significantly different services, resulting in either benefits or threats.

The second issue concerns technical uncertainties as those linked to the mapping process; for instance, inaccuracy of spatial data, mapping limitations, integration of data of varying quantity and quality (Liquete et al., 2015) or substantial differences between mapping approaches. Clearly, manual digitizing of all GI elements due to its huge time consumption is not an option. Mapping approaches based on automatic or semi-automatic classification procedures extracting data from satellite or aerial imagery could have the potential to overcome these limitations. For instance, Kopecká et al. (2017) proposed a mapping method focused on Urban Green Spaces (UGS) that combines semi - automatic UGS extraction from Sentinel data and classification of the extracted polygons based on visual interpretation of aerial orthophotos; thus, the manual digitising is minimised while maintaining a high level of accuracy. However, the GI concept comprises of a great many interpretational nuances and a wide variety of landscape elements that are often difficult to identify and classify even by ex-situ visual interpretation methods. It should be stressed that GI strategies are strongly linked to territorial planning development at each spatial level. Therefore, the approach should be transferable within levels and achievable for all public bodies involved in territorial planning and development, from local or regional through to national.

In this regard, more standardised and simplified GI mapping methods based on available land cover/land use data would be desirable. In the Czech Republic context this is not yet a very accessible task, free neither of complications nor additional adjustments. Likewise, this matter extends to other countries in Europe. CORINE Land Cover has been the only data set covering the entire European continent consistently, but with rather limited spatial detail. Other data sets have provided much better detail, but have lacked coverage (e.g. Urban Atlas) or have been thematically restricted (e.g. Copernicus High Resolution Layers) (Rosina et al., 2018). Many countries, however, have access to their national and regional datasets. Combination of these datasets could provide national/regional GI maps, which could be comparable if using common classification scheme, suggested either here or in Interreg Central Europe Project MaGICLandcapes output dealing with GI assessment (Ed., 2019).

Datasets should meet the requirements of the desired mapping level. In the Czech Republic context, it means more complications at the regional and local level since the degree of detail needed is often higher than the current existing means. We must also consider the existence of another territorial planning tool, the TSES - with a longer history and deeper roots within the national policies it could imply both weaknesses and strengths to GI strategies' implementation. TSES is a mandatory part of the territorial plans and therefore it could be an important source of data from national to local scale. Moreover, the elements contained in territorial plans are not only the already existing ones but also those, which are planned but not realised yet, or those, which are in the process to be realised. This allows a good perspective on future changes in land uses and therefore it provides a good basis for GI assessment and for setting priorities for territorial development. However, it should be stressed that TSES does not include all GI elements and therefore cannot be used as the only source for GI mapping. 


\section{CONCLUSIONS}

The GI mapping at a national level implies a large mapping area where additional manual editing or delineation would be very time consuming and resources demanding. Thus, the use of yet existing data sources on land cover is a must. CORINE Land Cover data Level 3 would offer a broad overview of the GI distribution and landscape connectivity but would not capture all necessary links visible even on the national level. Therefore, the use of the CLE data would be better. It would allow a more exhaustive GI assessment, although it is important to take into account its aforementioned limitations, especially in urban settings. As Wright (2011) suggests, an environmental focus for GI is fundamental to secure its objectives, but is it not enough (Liquete et al., 2015). According to McDonald et al. (2004), the GI concept aims to protect the ecological functions alongside providing benefits to humans. Thus, the economic and social benefits that the landscape provides often lack sufficient representation when the mapping is exclusively based on the habitat type approach.

The regional level mapping obviously requires higher accuracy and degree of detail than the national level. Since the mapping area is significantly smaller, the suggested procedure based on the utilisation of available data and additional manual editing is, in this case, achievable. The results accomplished represent a significant upgrade in accuracy with respect to the other approaches presented here. Nonetheless, manual editing and delineation is time consuming. Therefore using CLE data and modifying them for the urban areas in order to capture GI in these settings might be easier and faster way to create regional GI map with sufficient detail.

The local level mapping entails a great level of detail, which is currently not achievable using existing sources in the Czech Republic and many other countries. Additional methods to improve accuracy and reduce the size of the mapping unit are needed. A detailed regional map resulting from the above-mentioned procedure would be a good basis for the local level mapping. Manual delineation of smaller elements and refining of existing features on the regional map based on time-consuming but necessary fieldwork would be desirable in order to allow a proper GI assessment and planning at such scale. Local knowledge transferable to spatial data or TSES and other ecological network plans might be very useful supplementary information for a more satisfactory and usable result.

To summarize, using internationally based databases, such as CORINE Land Cover, is suitable for transnational studies and will provide brief overview of existing (as well as past) GI in Europe. For the national and regional level, careful combination of existing national and regional data can yield very good results about GI distribution. Some details about particular GI classes could be missing, depending of the classification scheme applied. However, the overall amount of GI and its distribution would be mostly accurate. Mapping GI on local level will not be possible without extensive and time-consuming fieldwork. Still, carefully prepared regional maps (either by combination of existing data and manual editing, as shown here, or with the help of remote sensing) will allow for faster procession of the local GI map.

\section{ACKNOWLEDGEMENTS}

The work presented here is a result from the international project MaGICLandscapes (Management of Green Infrastructure in Central European Landscapes) funded by INTERREG CENTRAL program, co-financed by ERDF. 


\section{REFERENCES}

Act No. 114/1992 Call. On nature conservation and Landscape protection.

Act No. 289/1995 Call. On forests (Forest Act).

Agger, P. \& Brandt, J., (1988). Dynamics of small biotopes in Danish agricultural landscapes, Landscape Ecology 1, 227-240. DOI: 10.1007/BF00157695.

AOPK ČR, (2013). Consolidated Layer of Ecosystems. Version 2013, Nature Conservation Agency of the Czech Republic, Prague.

Bínová, L., Culek, M., Glos, J., Kocián, J., Lacina, D., Novotný, M. \& Zimová, E. (2017). Methodology of defining Territorial system of ecological stability. MŽP, Praha.

Bossard, M., Feranec, J. \& Otahel, J., (2000). CORINE land cover technical guide Addendum 2000. EEA Technical report No. 40. EEA, Copehagen.

Buček, A., Maděra, P. \& Úradníček, L.., (2012). Czech approach to implementation of ecological network. Journal of Landscape Ecology, 5 (1), 14-28. DOI: 10.2478/v10285-012-0046-8.

Buček, A., Habrová, H., Maděra, P., Král, K., Modrý, M., Lacina, J. \& Pavliš, J., (2015). Application of the Czech methodology of Biogeographical landscape differentiation in geobiocoenological concept - examples from Cuba, Tasmania and Yemen. Journal of Landscape Ecology, 8 (3), 51-67. DOI: 10.1515/jlecol-2015-0014.

Collective, (2010). Creating Green Infrastructure for Ireland. Retrieved on 10 February 2019 from: http://edepositireland.ie/bitstream/handle/2262/71873/Comhar_27_2010.pdf? sequence $=1 \&$ is Allowed $=\mathrm{y}$.

Demková, K. \& Lipský, Z. (2017). Comparison of the current state of non-forest woody vegetation in two contrasted case study areas in Central Europe, Moravian Geographical Reports 23(4), 24-33. https://doi.org/10.1515/mgr-2017-0003.

Dennis, M., Barlow, D., Cavan, G., Id, P. A. C., Gilchrist, A., Handley, J., James, P., Thompson, J., Tzoulas, K., Wheater, C.P. \& Lindley, S., (2018). Mapping Urban Green Infrastructure: A Novel Landscape-Based Approach to Incorporating Land Use and Land Cover in the Mapping of Human-Dominated Systems. Land, 7. DOI: 10.3390/land7010017.

Interreg Central Europe Project MaGICLandcapes (Editors), (2019). Manual of Transnational Green Infrastructure Assessment - Decision Support Tool. Project Output O.T1.2. With contributions from: Neubert, M., John, H., Marrs, C., Alberico, S., Bovo, G., Ciadamidaro, S., Danzinger, F., Erlebach, M., Freudl, D., Grasso, S., Hahn, A., Jala, Z. Lasala, I., Minciardi, M., Rossi. G.L., Skokanová, H., Slach, T., Uhlemann, K., Vayr, P., Wojnarowicz, D., Wrbka, T. Published online. Retrieved on 10 February 2019 from:https://www.interregcentral.eu/Content.Node/MaGICLandscapes.html.

European Commission, (2013). Green Infrastructure (GI) - Enhancing Europe's Natural Capital. Communication from the Commission to the European Parliament, the European Economic Council, The European Economic and Social Committee and the Committee of the Regions. DOI: 10.1017/CBO9781107415324.004.

European Union, (2018). Mapping and Assessment of Ecosystems and their Services. An analytical framework for mapping and assessment of ecosystem condition in EU. DOI: $10.2779 / 41384$.

Firehock, K., (2010). A Short History of the Term Green Infrastructure and Selected Literature. Retrieved on 10 February 2019 from: http://www.gicinc.org/PDFs/GI\% 20History.pdf (accessed 10/02/2019). 
Jedicke, E., (1994). Biotopverbund. Ulmer Verlag, Stuttgart.

John, H., Neubert, M. \& Marrs, C., (2019). Green infrastructure handbook - Conceptual \& Theoretical Background, Terms and Definitions. First output of the Interreg Central Europe project MaGICLandscapes - Managing green infrastructure in Central European Landscapes. Published online, Retrieved on 10 February 2019 from: https://www.interreg-central.eu/ Content.Node/MaGICLandscapes.html.

Kopecká, M., Szatmári, D., \& Rosina, K., (2017). Analysis of Urban Green Spaces Based on Sentinel-2A: Case Studies from Slovakia, Land, 6. DOI: 10.1007/BF01060782.

Lammers, G.W., van Zadelhoff, F.J., (1996). The dutch national ecological network. In: P. Nowicki et al. (Ed): Perspectives on ecological networks. (p. 101-113). European Centre for Nature Conservation.

Liquete, C., Kleeschulte, S., Dige, G., Maes, J., Grizzetti, B., Olah, B., \& Zulian, G., (2015). Mapping green infrastructure based on ecosystem services and ecological networks: A Pan-European case study. Environmental Science and Policy, 54, 268-280. DOI: 10.1016/j.envsci.2015.07.009.

Löw, J., et al., (1995). Designer's handbook about territorial system of ecological stability, Brno.

Maes, J., Braat, L., Jax, K., Hutchins, M., Furman, E., Termansen, M, et al., (2011). A spatial assessment of ecosystem services in Europe: Methods, case studies and policy analysis phase 1. PEER Report 3. PEER Report No 3. Retrieved on 10 February 2019 from: https://www.peer.eu/files/user_upload/user_upload/publications/PEER_report_3_phase_1. df.

Mander, Ü., Kull, A., Uuemaa, E., Mõisja, K., Külvik, M., Kikas, T., Raet, J., Tournebize, J. \& Sepp, K., (2018). Green and brown infrastructures support a landscape-level implementation of ecological engineering. Ecological Engineering, 120, 23-35. DOI: 10.1016/j.ecoleng.2018.05.019.

McDonald, L., Allen, W., Benedict, M., \& Connor, K. O. (2004). Green Infrastructure Plan Evaluation Frameworks, Journal of Conservation Planning 1, 12-43.

McKenna D., Losarcos Escalera, L., Romero Vaquero, L., Tucker, G, \& Mazza, L., (2010). Green infrastructure in-depth case analysis. Theme 7: Mapping for planning. Retrieved on 10 February 2019 from: https://ieep.eu/uploads/articles/attachments/3ad4f433-60a0 -4b51-ad9c-fdaef470943f/GI_Case_Analysis_7_-_Mapping_For_Planning.pdf?v=6366450 9767.

Rosina, K., Batista, F., Vizcaino, P., Herrera, M. M., Freire, S., \& Schiavina, M., (2018). Increasing the detail of European land use/cover data by combining heterogeneous data sets. International Journal of Digital Earth, 13, 602-626. DOI: 10.1080/17538947.2018.1550119

Rosina, K., \& Kopecká, M., (2016). Mapping of urban green spaces using sentinel-2A data: Methodological aspects, in: Bandrova, T., Konecny, M (ed): 6th International conference on cartography and GIS, Vols. 1 and 2, (pp. 13-17).

Seják, J., (2010). Evaluation of functions and services of ecosystems of the Czech Republic. Univerzita Jana Evangelisty Purkyně v Ústí nad Labem, Ústí nad Labem.

Skokanová, H., (2018). Transnational remote-sensing-based GI-assessment report on ground-truthing - Kyjovsko region, Silva Tarouca Research Institute for Landscape and Ornamental Gardening, Brno.

Špulerová, J., Petrovič, F., \& Mederly, P., (2018). Contribution of Traditional Farming to Ecosystem Services Provision: Case Studies from Slovakia. Land, 7. DOI: 
10.3390/land7020074.

Topercer, J., (1995). Ecological comments on territorial system of ecological stability. Ekologia-Bratislava 14(3), 303-315.

Trnka, M., Balek, J., Štěpánek, P., Zahradníček, P., Možný, M., Eitzinger, J., Žalud, Z., Formayer, H., Turňa, M., Nejedlík, P., Semerádová, D., Hlavinka, P., Brázdil, R., (2016). Drought trend over part of Central Europe between 1961 and 2014. Climate Research 70, 143-160. DOI: 10.3354/cr01420.

Vačkář, D., Frélichová, J., Lorencová, E., Pártl, A., Loučková, B., (2015). Methodological framework of integrated assessment of ecosystem services in the Czech Republic. Global Change Research Center of the Academy of Sciences of the Czech Republic, Praha.

Wright, H., (2011). Understanding green infrastructure: the development of a contested concept in England, Local Environment, 16, 1003-1019. DOI: 10.1080/13549839. 2011.631993. 